\title{
Nurses' Practical Wisdom for the Support of Dementia Patients Among Hospital Outpatients
}

\author{
Utako Shimizu ${ }^{1}$, Kimiko Uehara ${ }^{2}$, Kiyomi Karasawa ${ }^{2}$, Kaori Ishizaki ${ }^{3}$, Tomoko Nonaka ${ }^{4}$, Mutsumi Ike ${ }^{2}$, \\ Chieko Fukuda ${ }^{4}$, Megumi Taguchi ${ }^{5} \&$ Hagiko Aoki $^{6}$ \\ ${ }^{1}$ Graduate School of Health Sciences, Niigata University, Niigata, Japan \\ ${ }^{2}$ Graduate School of Nursing, Niigata Seiryo University, Niigata, Japan \\ ${ }^{3}$ Nursing department, Shinrakuen Hospital, Niigata, Japan \\ ${ }^{4}$ Nursing department, Niigata University Medical and Dental Hospital, Niigata, Japan \\ ${ }^{5}$ School of Health Sciences Faculty of Medicine, Niigata University, Niigata, Japan \\ ${ }^{6}$ Faculty of Nursing, Chukyo Gakuin University, Gifu, Japan \\ Correspondence: Utako Shimizu, Graduate School of Health Sciences, Niigata University, 2-746 Asahimachi-dori, \\ Chuo-ku, Niigata 951-8518, Japan. Tel/Fax: 81-25-227-2371. E-mail: shirakaba@clg.niigata-u.ac.jp
}

Received: March 22, 2018 Accepted: April 8, 2018 Online Published: April 18, 2018

doi:10.5539/gjhs.v10n5p127

URL: https://doi.org/10.5539/gjhs.v10n5p127

\begin{abstract}
Purpose: To establish and understand nurses' practical wisdom and interventions of support for dementia and possible dementia patients at hospital outpatient wards.

Methods: A qualitative design was used to collect data through semi-structured focus group interviews. The participants were 13 female nurses working at hospital outpatient wards. Data were analyzed using the KJ Method.

Results: Seven themes symbolizing the properties of the final label were extracted as follows: 'Observation of patients with focused awareness, and are continuously engaged with their patients', 'Approach to the problems of the patients, and sensitively work to understand the worries of patients based on past cases of problems', 'Looking out for simple ways patients can look after themselves, implicitly and thoroughly, making the best use of the ways that patients are familiar with and which they are able to understand', 'Preparations for scheduled consultations by developing a network to assist with problem prevention and recording episodes about problems involving the patients', 'Requests for cooperation to continue treatment by choosing intermediaries/resources appropriately as based on the importance of the medical treatment', 'Responses that do not conflict with the feelings of the family by considering the possible reluctance of accepting that a family member has dementia', and 'Attitude not to blame matters on dementia by reflecting on how the environment and care ought to be'.
\end{abstract}

Conclusion: Nurses' practical wisdom is a type of support provided for patients in a natural manner without being noticed as special or particular by the patients.

Keywords: dementia, hospital outpatient, nursing, qualitative research, KJ Method

\section{Introduction}

The population of Japan is aging at a pace that is unparalleled in other countries; the percentage of the population aged above 65 was $26.7 \%$ as of October 1, 2015, and the number with dementia 4.62 million in 2012. This accounted for 1 in 7 of the elderly (aged 65 and over, a ratio of 15.0\%) and this number is expected to increase to about 7 million by 2025 (Cabinet Office, Japan., 2016). The Ministry of Health, Labour, and Welfare published the so-called Orange Plan, which envisioned to establish health care, social care, and advocacy services for persons with dementia in the 2013 to 2017 period. Under a new orange plan introduced from 2015, the basic concept is the aim to realize a society where dementia afflicted are able to live with dignity in an environment they are used to, to enable them to be able to live as long as possible (Nakanishi \& Nakashima, 2014; Ministry of Health, Labour and Welfare, Japan., 2016a). It is therefore imperative that development of a support system for dementia and possible dementia patients among hospital outpatients.

However, in Japan, the percentage of hospitals with waiting times longer than 30 minutes before the medical 
examination is $48.1 \%$ at large hospitals (over 500 beds) and $44.8 \%$ at medium sized hospitals (100 to 500 beds) even when making reservations in advance (Ministry of Health, Labour and Welfare, Japan, 2016b). At the same time the ratio of medical examinations lasting less than 10 minutes were $67.3 \%$ at large hospitals and $69.6 \%$ at medium sized hospitals (Ministry of Health, Labour and Welfare, Japan, 2016b). In previous research, the difficulties with care for dementia patients with cardiac insufficiency at hospital outpatient wards have been identified as: patients do not understand the explanations of the medical staff, staff having difficulties in learning about subjective symptoms, high risks of tumbling or falling, patients resist undergoing medical procedures and checking, patients present a nuisance to other patients, and patients may disappear from the hospital without permission (Otus, 2013). However, ways of caring for dementia and possible dementia patients at hospital outpatient wards have not been clearly established.

Knowledge gained through research is still essential, but alone it is insufficient for establishing practice. Aristotle advocated phronesis or practical wisdom, which is the virtue that enables a person to know how to act not because of some formulaic response to a given situation or set of circumstances but because of the development of a particular set of personal characteristics or virtues (Aristotle, 2009; Sellman, 2009). The research of Patricia Benner has demonstrated that teasing out and sharing acquired skills and ethics in the care practices can preserve and convey such skills to others (Benner., 1999; Benner et al., 2009, 2010, 2011). Because it is known that expert nurses have the practical wisdom and understanding of the activities needed (Benner et al., 2011), it is important to record and interpret the ways and experience of care for dementia and possible dementia patients held by expert nurses at hospital outpatient wards. The purpose of this study is to establish and understand nurses' practical wisdom and interventions of support for dementia and possible dementia patients when nurses discontinue general ambulatory practice based on listening to and by reporting what experienced nursing involves at hospital outpatient wards.

\section{Method}

A qualitative descriptive design was used to collect data through semi-structured focus group interviews.

\subsection{Participants}

A total of 14 participants were selected by head nurses at different hospital outpatient wards. The participants were registered nurses working at hospital outpatient wards as follows: (1) Affiliated with hospitals with 100 or more beds, (2) with 5 or more years of nursing experience and 3 years with hospital outpatients, and (3) Having experience of support for dementia and possible dementia patients at hospital outpatient wards.

\subsection{Data Collection}

Data were collected from semi-structured focus group interviews conducted in Japanese by one to three of the authors, using an interview guide containing open-ended questions. Focus groups are also useful in generating a rich and detailed understanding of participants' experiences and beliefs (Morgan, 1998). In focus groups, the universal experience of the group members is regarded as important (Holloway et al, 2002/ 2006). To promote an active discussion in small groups involving 2-3 participants, participants in the focus groups were nurses working in the same outpatient ward. Interviewers were not acquainted with the participants. Data were collected between November 2016 and April 2017. Four focus interview groups of 2-6 participants took part (Table 1). The interview sessions lasted from 50 to $80 \mathrm{~min}$, and were conducted according to the interview guide. Questions focused on, (1) feelings of what was considered important to support dementia and possible dementia patients at hospital outpatient consultations, (2) actions to take when the interview participants think a patient could suffer from dementia, (3) experience of feeling difficulties in the support for these patients, and (4) know-how of the support for the patients. Interview participants were asked to speak freely about their past experiences.

All interviews were audio recorded, and later transcribed verbatim in Japanese, and the ideas and observations that arose during the interviews were recorded.

\subsection{Data Analyasis}

Data were analyzed using the qualitative synthesis method developed by Jiro Kawakita (the KJ Method). This method has been helpful in extracting issues in nursing care from participants telling about the facilities they are working at. Three processes are involved in the data treatment in the KJ method: code making, grouping, and chart development (Kawakita., 1967, 1970; Yamaura., 2008). Code determination was conducted as follows: The data (codes) obtained were then organized into units by focusing on the experience in the care of dementia and possible dementia patients and by breaking down sentences into the smallest possible units so as not to overlook any of the thoughts expressed by the participants. These units of data were identified as codes. The codes were formed into groups based on similarities between the main themes represented by specific codes. After the initial grouping, a 
short summary was developed to describe the specifics of all the codes that were included in each group. This short summary was used as a label to identify the group in the next step; this was the first step in the process of the grouping. The process was repeated until approximately seven labels had been identified, and these were arranged spatially in a chart. The relationships and interconnections between the labels in the final groupings were identified. The core ideas expressed in the labels in the final groupings were rephrased into a short expression, which was theme symbolizing the properties of the final label. This process is called chart development.

The process and methodology of the analytical process were also discussed by the investigators who all possessed expertise in dementia nursing, as well as by qualified nurses and investigators with experience in qualitative research, to ensure accuracy and reliability. All categories, concepts, and variations were originally in Japanese and analyzed as such. The author translated these data into English, and a native English translator verified the translations.

\subsection{Ethical Considerations}

The study was approved by the Ethical Review Board of Niigata University School of Medicine (Approval No. 2633). The study conforms to the principles of the Declaration of Helsinki. Informed consent was obtained both verbally and in writing from the participants. All participants were informed to ensure their understanding that participation was voluntary and that they could withdraw from the study at any time without penalty. In the interviews, the participant convenience was considered the first priority. The interview was discontinued and rescheduled if required by the participants.

\section{Results}

\subsection{Summary of Participants (Table 1)}

The participants in this study were 13 female nurses with 3 to 12 -years of experience of outpatient assignments, and belonging to emergency, neurosurgery, dentistry, general surgery, orthopedic surgery, and/or internal medicine departments at three participating hospitals (A, B, and C). The numbers of beds at the A, B, and C hospitals were 454, 827 and 325, respectively.

Table 1. Summary of participants

\begin{tabular}{|c|c|c|c|c|c|c|c|c|}
\hline $\begin{array}{l}\Omega \\
0 \\
\vdots \\
Z \\
Z \\
0\end{array}$ & 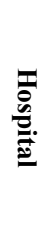 & 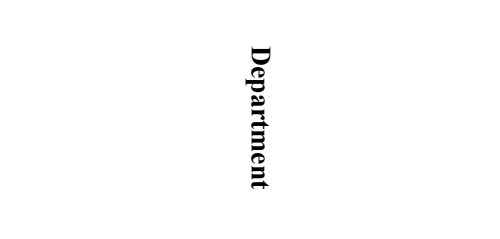 & 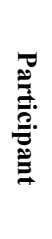 & $\begin{array}{l}\Omega \\
\stackrel{9}{0} \\
\stackrel{2}{9}\end{array}$ & 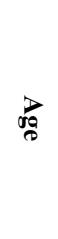 & 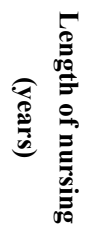 & 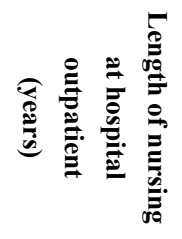 & 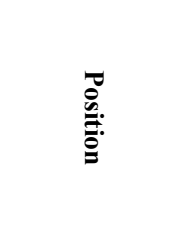 \\
\hline \multirow[t]{2}{*}{1} & A & Emergency visit & A & $\mathrm{F}$ & $50 \mathrm{~s}$ & 34 & $\begin{array}{c}\text { Between } 5 \text { and } \\
10\end{array}$ & $\begin{array}{c}\text { Assistant head } \\
\text { nurse }\end{array}$ \\
\hline & A & Neurosurgery Emergency visit & $\mathrm{B}$ & $\mathrm{F}$ & $30 \mathrm{~s}$ & 16 & 10 & Chief nurse \\
\hline \multirow{3}{*}{2} & B & Surgical & $\mathrm{C}$ & $\mathrm{F}$ & $50 \mathrm{~s}$ & 38 & 4 & Staff \\
\hline & $\mathrm{B}$ & Surgical & $\mathrm{D}$ & $\mathrm{F}$ & $40 \mathrm{~s}$ & 18 & 4 & Staff \\
\hline & $\mathrm{B}$ & Surgical & $\mathrm{E}$ & $\mathrm{F}$ & $50 \mathrm{~s}$ & 36 & 3 & $\begin{array}{c}\text { Assistant head } \\
\text { nurse }\end{array}$ \\
\hline \multirow[t]{2}{*}{3} & B & Dentistry & $\mathrm{F}$ & $\mathrm{F}$ & $50 \mathrm{~s}$ & 31 & 4 & $\begin{array}{l}\text { Assistant head } \\
\text { nurse }\end{array}$ \\
\hline & $\mathrm{B}$ & Dentistry & G & $\mathrm{F}$ & $20 \mathrm{~s}$ & 8 & 4 & Staff \\
\hline \multirow{6}{*}{4} & $\mathrm{C}$ & Internal medicine, Emergency visit & $\mathrm{H}$ & $\mathrm{F}$ & $50 \mathrm{~s}$ & 31 & 5 & Staff \\
\hline & $\mathrm{C}$ & $\begin{array}{l}\text { Orthopedic surgery, Endoscopic } \\
\text { examination }\end{array}$ & I & $\mathrm{F}$ & $40 \mathrm{~s}$ & 25 & 11 & Staff \\
\hline & $\mathrm{C}$ & Gastroenterology & $\mathrm{J}$ & $\mathrm{F}$ & $50 \mathrm{~s}$ & 37 & 12 & Chief nurse \\
\hline & $\mathrm{C}$ & Endocrinology and Metabolism & $\mathrm{K}$ & $\mathrm{F}$ & $40 \mathrm{~s}$ & 22 & 10 & Staff \\
\hline & $\mathrm{C}$ & Surgical, Endoscopic examination & $\mathrm{L}$ & $\mathrm{F}$ & $30 \mathrm{~s}$ & 18 & 10 & Chief nurse \\
\hline & $\mathrm{C}$ & Gastroenterology, Gastrointestinal Surgery & M & $\mathrm{F}$ & $40 \mathrm{~s}$ & 20 & 4 & Staff \\
\hline
\end{tabular}




\subsection{Results of the Analysis}

The number of labels created from the interviews of the four groups was 202, and these were finally narrowed down to seven labels through four repeated processes of grouping. Table 2 shows the results of the analysis summarized by the themes symbolizing the properties of the final label, final labels, and the labels one level previous. Single quotation notation (') is used for themes symbolizing the properties of the final label, square brackets ([ ] ) for the final labels, and angular brackets $(<>)$ for the sub-labels.

3.2.1 'Observation of Patients With Focused Awareness of: Being Continuously Engaged in Patients as far as the Faculties Allow'

The final label here is [I try to remain engaged in the patients undividedly as far as my faculties allow with an awareness that dementia is involved], and includes the following sub-labels: $<$ I think the beginning of dementia is signaled when the patients are looking around restlessly, absentminded, not caring about the own appearance, not able to do what they were able to before, and becoming short-tempered $>$, and $<$ I try to watch out for the patients I care for as far as my faculties allow by listening carefully and patiently when being engaged with them $>$. These illustrate how nurses prepare themselves to respond to patients at any time rather than approach the patients too soon while still noticing slight signs and changes in the patients.

3.2.2 'Approach to the Problems of the Patients: Sensitively Work to Understand the Worries of Patients Based on Past Cases of Problems'

The final label here is [I try to identify clues to help me get involved with patients by focusing on the problems patients have, responding to their problems, and understanding them while keeping eye contact]. This includes $<\mathrm{I}$ try to identify clues to help me get involved with patients by paying close attention to whether they are experiencing troubles keeping eye contact, and notice changes in interests and facial expressions of patients $>$, and $<$ I try to lead patients to the toilet well in advance of being asked so that patients will be able to relieve themselves in a timely fashion without fail, and to ensure I have diapers available>. These expressions illustrate that nurses take care of the patients by sensing possible problems what are not clearly expressed or requested by the patients.

3.2.3 'Looking out for simple ways patients can look after themselves: implicitly and thoroughly, making the Best Use of the Ways That Patients Are Familiar With and Which They Are Able to Understand'

The final label here is [I try to explain matters in an easy-to-grasp manner by working with the five senses of patients so that the patients can complete the procedures for consultation by themselves in accordance with ways they are able to deal with and at their own pace]. This includes $<$ I try to find ways so patients understand, and I explain to the patients without making patients feel or sense that nurses have made the arrangements $>$, and $<\mathrm{I}$ make effort to perceive the wishes, preferences, and possible refusal, and wait until patients are able to understand and comply>. These illustrate that nurses respect the identity and individual emotional needs of the patients, and make efforts to provide assistance according to the wishes of individual patients.

\subsection{4 'Attitude Not to Blame Matters on Dementia: Reflecting on How the Environment and Care Ought to Be'}

The final label here is [I reflect on the environment and ways of giving explanations when patients become missing and cannot conduct activities according to the explanations, rather than blaming the patients with dementia]. Sub-labels here are $<$ When patients have become missing, I reflect on whether my explanations and responses were difficult to understand, and do not blame the patients with dementia for the occurrences $>,<$ When patients have become missing, we look for them everywhere inside and outside of the hospital until we are able to confirm that they are safe $>,<$ As a nurse I want to escort patients to their destination, but I cannot always leave an assigned duty $>$, and $<$ As the reception procedure is complicated, I often think that it is convenient for patients if staff can respond directly to patients here $>$. These matters illustrate that nurses think it natural that symptoms of dementia bring about problems and trouble, and think that reception and outpatient arrangements have issues that could be improved.

3.2.5 'Preparations for Scheduled Consultations: Developing a Network to Assist With Problem Prevention by Recording Episodes About Problems Involving the Patients'

The final label here is [I am ready with some mechanisms that help prevent trouble based on past episodes about problems involving patients who need special attention, to ensure that consultations will be provided as scheduled]. This includes $<$ I am ready with actions to prevent patients who caused problems in the past from repeating the problems by recording episodes about problems involving the patients $>,<$ We develop a network of staff to respond to patients by sharing information among the staff $>,<$ A nurse escorts patients who cannot find their way around the outpatient department alone and/or a different member of the staff looks after the patient. We never let 
the patient remain unattended $>$, and $<$ Look for information in advance, and if a patient is suffering from dementia and/or aged 80 and over, we actively get involved with the patient>. These labels report that nurses prepare measures to avoid problems through organizational efforts and by updating information, and ensure that patients are able to undergo consultations as scheduled. Patient

3.2.6 'Requests for Cooperation to Continue Treatment: Choosing Intermediaries/Resources Appropriately as Based on the Importance of the Medical Treatment'

The final label here is [After deciding on the priority of consultation, examination, decision making, and treatment continuity, we contact the patient, have the family visit the hospital, and seek cooperation from professionals other than at the hospital to carry out the plans]. This label includes $<$ When it is decided to conduct a consultation, examination, and/or make decisions as important for the medical treatment, we employ every possible measure to get the family to visit the hospital, including use of telephoning and telegrams $>$, and $<$ We request to have other professionals and resources available to respond to patients who need to change medications because changing medications often requires more time than outpatient nurses have available $>$. These matters illustrate that nurses seek cooperation in appropriate places when evaluating needs for an active approach to ensure that patients continue treatment.

3.2.7 'Responses That Do Not Conflict With the Feelings of the Family: Considering the Possible Reluctance of Accepting That a Family Member Has Dementia'

This final label here expresses that it is [Sometimes difficult to obtain support from families because they do not accept that a member of their family has dementia. But I am accepting their feelings and trying to get involved with families while making effort to gradually make them understand that a member of the family has dementia, instead of insisting on them to accept the diagnosis of dementia and expecting them to actively support the patient]. This label includes $<$ I do not impose my ideas on the families when I cannot obtain cooperation from families to support patients because the families do not accept that a member of their family has dementia, when their ideas are different from mine $>,<$ I try to communicate with the families of patients as usual, and tell them about the symptoms of dementia little by little for their better understanding of dementia $>$. These illustrate that nurses see the families of patients as needing support from the medical profession, as well as that the nurses expect them to play a role in supporting the patients.

\subsection{Structure of Nurses' Practical Wisdom for the Support of Dementia and Possible Dementia Patients}

Figure 1 shows a schematic diagram that illustrates relationships among the seven themes symbolizing the properties of the final label described above. Nurses working in outpatient wards pay close attention to patients who need support of the cognitive functions, among all of the outpatients in their care, and conduct 'Observation of patients with focused awareness, and are continuously engaged with their patients as far as their faculties allow', At the same time, nurses assume an 'Approach to the problems of the patients, and sensitively work to understand the worries of patients based on past cases of problems'. Nurses are 'Looking out for simple ways patients can look after themselves, implicitly and thoroughly, making the best use of the ways that patients are familiar with and which they are able to understand' with the help by these two.

To create an environment that enables 'Looking out for simple ways patients can look after themselves', nurses conduct 'Preparations for scheduled consultations by developing a network to assist with problem prevention and recording episodes about problems involving the patients' and address 'Requests for cooperation to continue treatment by choosing intermediaries/resources appropriately as based on the importance of the medical treatment', while providing 'Responses that do not conflict with the feelings of the family by considering the possible reluctance of accepting that a family member has dementia'.

These strategies for providing the assistance are always based on an 'Attitude not to blame matters on dementia by reflecting on how the environment and care ought to be'. 


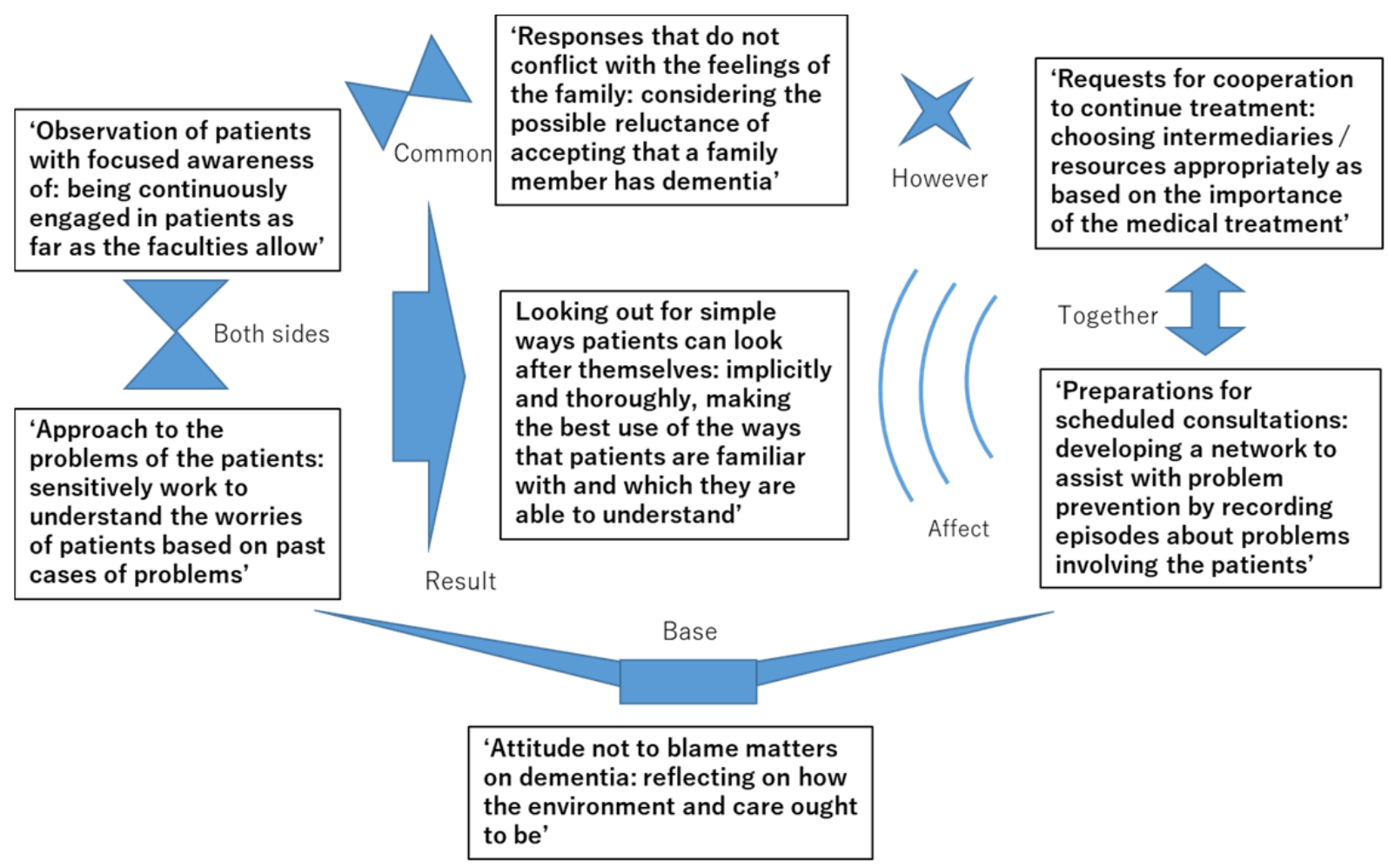

Figure 1. Schematic diagram of nurses' practical wisdom for the support of dementia and possible dementia patients among hospital outpatients

\section{Discussion}

In this study seven themes symbolizing the properties of the final label were extracted. These labels suggest that nurses in outpatient wards are skillfully responding to elderly patients with dementia, and that when any problems occur, nurses search for the reasons and background to the problem, and provide the care in accordance with the reasons and background that is determined. These findings would represent the situation that the experience of elderly patients with dementia and their families encounter in outpatient wards.

In epidemiological studies such as the Rotterdam Study (Ruitenberg et al., 2001), the Kungsholmen Project (Qiu et al., 2004), and the Hisayama Study (Matsui et al., 2009), high blood pressure and diabetes have been reported as risk factors in dementia. In Japan, there are 10,110,000 patients undergoing blood pressure management and $3,170,000$ patients with diabetes, who are at high risk of developing dementia (Ministry of Health, Labour and Welfare., 2016c). Therefore, the possibility of outpatients with other complaints developing dementia under medical treatment is high, and it can be inferred that there are dementia and possible dementia patients in outpatient wards.

Patients who visit outpatient wards s are required to employ a lot of time to successfully complete the visit and consultation and to move around the hospital to contact various sections including the reception, examination, consultation, and accounting sections. Nurses in outpatient wards are aware of the behaviors of patients, such as "looking around restlessly, being absentminded, not caring about their own appearance, and being short-tempered" among the many outpatients moving busily in a hospital. A behavior like "looking around restlessly" may be due to unexpected movements of the sight line appearing when the patients try to identify their location but experience topographical disorientation (Strub et al., 2000/2005), or be due to changes in the sight line caused by deterioration in involuntary eye movement functions, a symptom of eye movement disorders seen in Alzheimer's disease patients. It is also reported that anxiety is related to problem behaviors in Alzheimer's disease (Ferretti et al., 2001).

According to a study (Lindbo et al., 2017) that investigated the cognitive function and incidence of Behavioral and Psychological Symptoms of Dementia (BPSD) among residents of elderly nursing homes and inpatients of wards for the elderly in Sweden, $56.6 \%$ of patients with dementia feel symptoms that they describe as uncomfortable regardless of the severity of the cognitive dysfunction, and the study also reported that BPSD is related to 
uncomfortable symptoms that appear together with these, such as aggressive behaviors. In heart failure patients with cognitive dysfunction who visit cardiovascular outpatient wards, $43.6 \%$ had symptoms of disturbance and $36.4 \%$ suffered from hyperactivity, and nurses of outpatient wards felt it difficult to respond to and deal with these patients (Otsu et al., 2013). It was suggested that elderly outpatients who need to attend consultations may feel irritated, and show restless and hyperactive behaviors due to the presence of uncomfortable symptoms caused by their physical conditions. It was found that nurses conduct 'Observation of patients with focused awareness' of changes in the eye movements and emotions of patients.

The hospitals of the nurses in outpatient wards who participated in this study were large (500 beds or more) and medium size (100 to 499 bed). The nurses were taking an 'Approach to the problems of the patient' to make the consultation more effective by <leading patients to the toilet well in advance of being asked so that patients will be able to relieve themselves in a timely fashion without fail, and asking the family member to prepare diapers, because the patients have had bitter experiences with this $>$. As participants in this study reported the experience of patients under their care who failed by relieving themselves in the outpatient waiting room, and there are patients with dementia who may have problems of frequent urination. With dementia, functional urinary incontinence is common, and increased urinary frequency and frequent urinary incontinence may occur even if the severity of the cognitive decline is mild (MMSE 21 - 30). The cause is considered to be detrusor over-activity (Kashiwabara et al., 2015), and $11 \%$ of patients living at home suffer from detrusor over-activity. Therefore, it is assumed that some outpatients have to go to the bathroom frequently.

The nursing practices of 'Observation of patients with focused awareness' and 'Approach to the problems of the patient' enables 'Looking out for simple ways patients can look after themselves'. Hirakawa, et al. (2017) have reported that obstacles for the dementia care provided for elderly persons with dementia to enable living in the community include poor hospital environments, insufficient time and space to provide the care, and absence of nurses who pay attention to the wishes of patients, and in that report pointed out the difficulties for professionals to practice nursing appropriate for patients with dementia. In this study, nurses in outpatient wards were engaged in improving the environments such as by creating networks of experienced staff to support dementia patients through cooperation with other professionals and departments, while exploring ways to make procedures for consultation and medication simpler so that patients with dementia would be able to perform these activities without help. In attempting this, nurses in outpatient wards were making the best use of the ways patients are familiar with and are implicitly aware of and determined to mask the intentions of the nurses providing the care from the patients so that the patients will be able to conduct the procedures by themselves.

In outpatient wards of large and medium sized hospitals, there are cases where patients with dementia go missing during long waiting times (Ministry of Health, Labour and Welfare, Japan., 2016b) and while on the way to various other sections of the hospital, such as the reception, examination rooms, and laboratory facilities. In this case, nurses in outpatient wards take action reported as $<$ When patients are missing, we look carefully for them inside and outside of the hospital, to confirm that they are safe $>$. This type of missing outpatient occurring during the waiting time may be caused by disorientation, impaired visuospatial ability with deterioration in parietal lobe functioning, or anxieties associated with these conditions (Shinagawa et al., 2011). It is reported that the comprehension and management abilities of elderly outpatients aged 65 and over tend to be poor, and that the score on the regimen comprehension scale (RCS) lowers with age, and even when there is no indication of dementia the RCS score is low (Yamada et al., 2001). Nurses in outpatient wards who are in contact with patients like those considered on a daily basis followed principles based on an 'Attitude not to blame matters on dementia' illustrated by the label [I reflect on the environment and ways of giving explanations when patients become missing and cannot conduct activities according to the explanations, rather than blaming the patients with dementia].

Finally, we wish to discuss the relationship with the family in caring for elderly people with dementia. In relation to the 'Requests for cooperation to continue treatment', nurses in outpatient wards sometimes request the families of patients to visit the hospital to have them help in decision making for the patients depending on the importance of the medical treatment. However, the nurses in outpatient wards here were providing 'Responses that do not conflict with the feelings of the family' by $<$ Not imposing my ideas on the families $>$ and $<$ Telling families about the symptoms of dementia little by little for their better understanding of dementia $>$ even if there is a difference in understanding of the patient conditions. This is because nurses in outpatient wards recognize that it is necessary for the families themselves to accept the dementia of the elderly family member, sympathizing with the feelings of the family members reluctant to accept the state of dementia. Families experience anxieties due to uncertainties about symptoms and causes, and feel isolated because their burden is caused by the disease and caregiving, something that cannot be shared with others from or after the appearance of symptoms to the diagnosis of dementia (Yasutake et al., 2007). Further, it is reported that if nurses encourage families to take care of the elderly family member with 
dementia, at the pace of understanding of the medical professionals, the families feel this as being pressured (Hayashi, 2005). The findings from this study suggest that one feature of nurses in outpatient wards is in providing support to help families understand the situation while also paying close attention to the burden these other family members are exposed to.

\section{Conclusions}

Traditionally, in providing support for dementia and possible dementia patients, nurses in outpatient wards make efforts to develop their practical wisdom by recording past noteworthy episodes involving the patients and reflecting on the environment for the consultation. This is a type of support provided for patients in a natural manner without being noticed or identified as special or particular by the patients. It is important that patients can conduct themselves for the purpose of simple consultation behaviors, activities that patients can perform by themselves and through this improving the environment of the consultation.

\section{Acknowledgements}

We would like to thank participants for cooperation in data collection. tudy. End this paragraph with thanks for personal assistance, such as in manuscript preparation.

\section{Competing Interests Statement}

The authors declare that there are no competing or potential conflicts of interest.

\section{References}

Aristotle. (2009). The Nicomachean Ethics (Revised edition) (Ross, D, Trans.). Oxford, UK: Oxford University Press.

Benner, P. (1999). From Novice to Expert: Excellence and Power in Clinical Nursing Practice (2nd ed.). Menlo Park, CA: Addison-Wesley.

Benner, P., Tanner, C., \& Chesla. C. (2009). Expertise in Nursing Practice: Caring, Clinical Judgment and Ethics (2nd ed.). New York, NY: Springer.

Benner, P., Sutphen, M., Leonard, V., \& Day, L. (2010). Educating Nurses: A Call for Radical Transformation. San Francisco, CA: Jossey-Bass.

Benner, P., Hooper, Kyriakidis, P., \& Stannard, D. (2011). Clinical Wisdom and Interventions in Acute and Critical Care (2nd ed.). New York, NY: Springer.

Cabinet Office, Japan. (2016). Annual report on the aging society FY 2016. http://www8.cao.go.jp/kourei/english/annualreport/2016/2016pdf_e.html

Ferretti, L., McCurry, S, M., Logsdon, R., Gibbons, L., \& Teri, L. (2001). Anxiety and Alzheimer's disease. $J$ Geriatr Psychiatry Neurol, 14, 52-8. https://doi.org/10.1177/089198870101400111

Ousu, H. (2013). Current status of complex nursing care and support given by nurses to elderly outpatients with dementia and chronic heart failure. Journal of Japanese Society for Dementia Care, 12, 619-630. (In Japanese)

Hayashi, Y. (2005). A change of marital relationships in a process of wives' receptiveness to caregiving roles for disabled husbands at home: A grounded theory approach. Japanese Journal of Gerontology, 27, 43-54. (In Japanese)

Hirakawa, Y., Chiang, C., \& Aoyama, A. (2017). A qualitative study on barriers to achieving high-quality, community-based integrated dementia care. J Rural Med, 12, 28-32. https://doi.org/10.2185/jrm.2927

Holloway, I., \& Wheeler, S. (2002/ 2006). Qualitative Reserch in Nursing (2nd ed.) (Noguchi, M., Trans.). Oxford, UK: Oxford University Press. (In Japanese)

Kashiwabara, R., Tateno, R., Kishi, M., Tuyuzaki, Y., Aiba, Y., Ogata, T., ... Sugiyama, M. (2015). Excretory disorder. Japanese journal of geriatric psychiatry, 26(supple 1), 89-98. (In Japanese)

Kawakita, J. (1967). Hassoho (Abduction). Tokyo, JPN: Chuokoron-Shinsha. (In Japanese)

Kawakita, J. (1970). Zoku Hassoho (Abd)uction: Part two). Tokyo, JPN: Chuokoron-Shinsha. (In Japanese)

Lindbo, A., Gustafsson, M., Isaksson, U., Sandman, P. O., \& Lövheim, H. (2017). Dysphoric symptoms in relation to other behavioral and psychological symptoms of dementia, among elderly in nursing homes. $B M C$ Geriatrics, 17(206), 1-8. https://doi.org/10.1186/s12877-017-0603-4 
Matsui, Y., Tanizaki, Y., Arima, H., Yonemoto, K., Doi, Y., Ninomiya, T., ... Kiyohara, Y. (2009). Incidence and survival of dementia in a general population of Japanese elderly: The Hisayama Study. $J$ Neurosurg Psychiatry, 80, 366-370. https://doi.org/10.1136/jnnp.2008.155481

McKie, A., Baguley, F., Guthrie, C., Jackson, C., Kirkpatrick, P., Laing, A., ... Wimpenny, P. (2012). Exploring clinical wisdom in nursing education. Nursing Ethics, 19, 252-267. https://doi.org/10.1177/0969733011416841

Ministry of Health, Labour and Welfare, Japan (2016a). Long-Term Care Insurance System of Japan. http://www.mhlw.go.jp/english/policy/care-welfare/care-welfare-elderly/dl/ltcisj_e.pdf

Ministry of Health, Labour and Welfare, Japan (2016b). Patient's Behavior Survey in FY 2014 (Final Number).

Ministry of Health, Labour and Welfare, Japan. (2016c). Summary of Patient Survey in 2014. Retrieved from http://www.mhlw.go.jp/toukei/saikin/hw/kanja/14/index.html

Morgan, D. L. (1998). The focus group guide book. Thousand Oaks, CA: Sage Publications. https://doi.org/10.4135/9781483328164

Nakanishi, M., \& Nakashima, T. (2014). Features of the Japanese national dementia strategy in comparison with international dementia policies: How should a national dementia policy interact with the public health- and social-care systems?. Alzheimers Dement, 10, 468-476. https://doi.org/10.1016/j.jalz.2013.06.005

Qiu, C., von Strauss, E., Winblad, B., \& Fratiglioni, L. (2004). Decline in blood pressure over time and risk of dementia: a longitudinal study from the Kungsholmen project. Stroke, 35, 1810-1815. https://doi.org/10.1161/01.STR.0000133128.42462.ef

Ruitenberg, A., Skoog, I., Ott, A., Aevarsson, O., Witteman, J. C., Lernfelt, B., ... Breteler, M. M. (2001). Blood pressure and risk of dementia: results from the Rotterdam study and the Gothenburg H-70 Study. Dement Geriatr Cogn Disord, 12, 33-39. https://doi.org/10.1159/000051233

Sellman, D. (2009). Practical wisdom in health and social care: teaching for professional phronesis. Learning in Health and Social Care, 8, 84-91. https://doi.org/10.1111/j.1473-6861.2009.00222.x

Shinagawa, S., \& Ikeda, M. (2011). Wandering and roaming, Nippon Rinsho, 69, 376-379.

Strub, R, L., \& Black, F, W. (2000/ 2005). The mental status examination in neurology (4th ed.) (Eto, F, Trans.). Philadelphia, PA: F. A. Davis Company.

Yamada, H., Sugiyama, T., Ashida, T., Ohwaki, \& H., Fujii. (2001). Medication management skill and regimen compliance are deteriorated in the elderly even without obvious dementia. Yakugaku Zasshi, 121, 187-190. https://doi.org/10.1248/yakushi.121.187

Yamaura, H. (2008). Theory and practice of the qualitative synthesis method (KJ Method) and "Cosmos Methodology" which creates conceptions. The Japanese Journal of Nursing Research, 41, 11-32. (In Japanese)

Yasutake, A., Igarashi, K., Fukushima, R., \& Kodama, T. (2007). A Family's Experience of the Elderly with Dementia: From the Onset of Symptoms to Being Diagnosed. Journal of Japan Academy of Gerontological Nursing, 12, 32-39. (In Japanese) 


\section{Appendix}

\section{Table 1. Labels list}

\begin{tabular}{|c|c|c|}
\hline $\begin{array}{l}\text { Themes symbolizing the properties of the } \\
\text { final label }\end{array}$ & Final label & Sub-label \\
\hline \multirow{2}{*}{$\begin{array}{l}\text { Observation of patients with focused } \\
\text { awareness of: being continuously engaged } \\
\text { in patients as far as the faculties allow }\end{array}$} & \multirow{2}{*}{$\begin{array}{l}\text { I try to remain engaged in the patients } \\
\text { undividedly as far as my faculties allow with } \\
\text { an awareness that dementia is involved. }\end{array}$} & $\begin{array}{l}\text { I think the beginning of dementia is signaled when the patients are looking } \\
\text { around restlessly, absentminded, not caring about the own appearance, not able } \\
\text { to do what they were able to before, and becoming short-tempered. }\end{array}$ \\
\hline & & $\begin{array}{l}\text { I try to watch out for the patients I care for as far as my faculties allow by } \\
\text { listening carefully and patiently when being engaged with them. }\end{array}$ \\
\hline \multirow{2}{*}{$\begin{array}{l}\text { Approach to the problems of the patients: } \\
\text { sensitively work to understand the worries } \\
\text { of patients based on past cases of } \\
\text { problems }\end{array}$} & \multirow{2}{*}{$\begin{array}{l}\text { I try to identify clues to help me get involved } \\
\text { with patients by focusing on the problems } \\
\text { patients have, responding to their problems, } \\
\text { and understanding them while keeping eye } \\
\text { contact. }\end{array}$} & $\begin{array}{l}\text { I try to identify clues to help me get involved with patients by paying close } \\
\text { attention to whether they are experiencing troubles keeping eye contact, and } \\
\text { notice changes in interests and facial expressions of patients. }\end{array}$ \\
\hline & & $\begin{array}{l}\text { I try to lead patients to the toilet well in advance of being asked so that patients } \\
\text { will be able to relieve themselves in a timely fashion without fail, and to ensure I } \\
\text { have diapers available. }\end{array}$ \\
\hline \multirow{2}{*}{$\begin{array}{l}\text { Looking out for simple ways patients can } \\
\text { look after themselves: implicitly and } \\
\text { thoroughly, making the best use of the } \\
\text { ways that patients are familiar with and } \\
\text { which they are able to understand }\end{array}$} & \multirow{2}{*}{$\begin{array}{l}\text { I try to explain matters in an easy-to-grasp } \\
\text { manner by working with the five senses of } \\
\text { patients so that the patients can complete the } \\
\text { procedures for consultation by themselves in } \\
\text { accordance with ways they are able to deal } \\
\text { with and at their own pace. }\end{array}$} & $\begin{array}{l}\text { I try to find ways so patients understand, and I explain to the patients without } \\
\text { making patients feel or sense that nurses have made the arrangements. }\end{array}$ \\
\hline & & $\begin{array}{l}\text { I make effort to perceive the wishes, preferences, and possible refusal, and wait } \\
\text { until patients are able to understand and comply. }\end{array}$ \\
\hline \multirow{4}{*}{$\begin{array}{l}\text { Attitude not to blame matters on dementia: } \\
\text { reflecting on how the environment and } \\
\text { care ought to be }\end{array}$} & \multirow{4}{*}{$\begin{array}{l}\text { I reflect on the environment and ways of } \\
\text { giving explanations when patients become } \\
\text { missing and cannot conduct activities } \\
\text { according to the explanations, rather than } \\
\text { blaming the patients with dementia. }\end{array}$} & $\begin{array}{l}\text { When patients have become missing, I reflect on whether my explanations and } \\
\text { responses were difficult to understand, and do not blame the patients with } \\
\text { dementia for the occurrences. }\end{array}$ \\
\hline & & $\begin{array}{l}\text { When patients have become missing, we look for them everywhere inside and } \\
\text { outside of the hospital until we are able to confirm that they are safe. }\end{array}$ \\
\hline & & $\begin{array}{l}\text { As a nurse I want to escort patients to their destination, but I cannot always } \\
\text { leave an assigned duty. }\end{array}$ \\
\hline & & $\begin{array}{l}\text { As the reception procedure is complicated, I often think that it is convenient for } \\
\text { patients if staff can respond directly to patients here. }\end{array}$ \\
\hline \multirow{4}{*}{$\begin{array}{l}\text { Preparations for scheduled consultations: } \\
\text { developing a network to assist with } \\
\text { problem prevention by recording episodes } \\
\text { about problems involving the patients }\end{array}$} & \multirow{4}{*}{$\begin{array}{l}\text { I am ready with some mechanisms that help } \\
\text { prevent trouble based on past episodes about } \\
\text { problems involving patients who need special } \\
\text { attention, to ensure that consultations will be } \\
\text { provided as scheduled }\end{array}$} & $\begin{array}{l}\text { I am ready with actions to prevent patients who caused problems in the past } \\
\text { from repeating the problems by recording episodes about problems involving the } \\
\text { patients. }\end{array}$ \\
\hline & & $\begin{array}{l}\text { We develop a network of staff to respond to patients by sharing information } \\
\text { among the staff. }\end{array}$ \\
\hline & & $\begin{array}{l}\text { A nurse escorts patients who cannot find their way around the outpatient } \\
\text { department alone and/or a different member of the staff looks after the patient. } \\
\text { We never let the patient remain unattended. }\end{array}$ \\
\hline & & $\begin{array}{l}\text { Look for information in advance, and if a patient is suffering from dementia } \\
\text { and/or aged } 80 \text { and over, we actively get involved with the patient. }\end{array}$ \\
\hline \multirow{2}{*}{$\begin{array}{l}\text { Requests for cooperation to continue } \\
\text { treatment: choosing intermediaries / } \\
\text { resources appropriately as based on the } \\
\text { importance of the medical treatment }\end{array}$} & \multirow{2}{*}{$\begin{array}{l}\text { After deciding on the priority of consultation, } \\
\text { examination, decision making, and treatment } \\
\text { continuity, we contact the patient, have the } \\
\text { family visit the hospital, and seek cooperation } \\
\text { from professionals other than at the hospital } \\
\text { to carry out the plans. }\end{array}$} & $\begin{array}{l}\text { When it is decided to conduct a consultation, examination, and/or make decisions } \\
\text { as important for the medical treatment, we employ every possible measure to } \\
\text { get the family to visit the hospital, including use of telephoning and telegrams }\end{array}$ \\
\hline & & $\begin{array}{l}\text { We request to have other professionals and resources available to respond to } \\
\text { patients who need to change medications because changing medications often } \\
\text { requires more time than outpatient nurses have available. }\end{array}$ \\
\hline \multirow{2}{*}{$\begin{array}{l}\text { Responses that do not conflict with the } \\
\text { feelings of the family: considering the } \\
\text { possible reluctance of accepting that a } \\
\text { family member has dementia }\end{array}$} & \multirow{2}{*}{$\begin{array}{l}\text { Sometimes difficult to obtain support from } \\
\text { families because they do not accept that a } \\
\text { member of their family has dementia. But I } \\
\text { am accepting their feelings and trying to get } \\
\text { involved with families while making effort to } \\
\text { gradually make them understand that a } \\
\text { member of the family has dementia, instead } \\
\text { of insisting on them to accept the diagnosis } \\
\text { of dementia and expecting them to actively } \\
\text { support the patient. }\end{array}$} & $\begin{array}{l}\text { I do not impose my ideas on the families when I cannot obtain cooperation from } \\
\text { families to support patients because the families do not accept that a member of } \\
\text { their family has dementia, when their ideas are different from mine. }\end{array}$ \\
\hline & & $\begin{array}{l}\text { I try to communicate with the families of patients as usual, and tell them about } \\
\text { the symptoms of dementia little by little for their better understanding of } \\
\text { dementia. }\end{array}$ \\
\hline
\end{tabular}




\section{Copyrights}

Copyright for this article is retained by the author(s), with first publication rights granted to the journal.

This is an open-access article distributed under the terms and conditions of the Creative Commons Attribution license (http://creativecommons.org/licenses/by/4.0/). 